\title{
Role of surfactant molecular weight on morphology and properties of functionalized graphite oxide filled polypropylene nanocomposites
}

\author{
Y. Wang ${ }^{*}, J-C$. Wang, S-Z. Chen \\ Department of Chemical and Materials Engineering Tunghai University, 407 Taichung, Taiwan, Republic of China
}

Received 15 April 2014; accepted in revised form 23 June 2014

\begin{abstract}
Various surfactants of different molecular weights, including alkylamine, poly(oxypropylene) diamine (POP), and maleic anhydride grafted polypropylene (PPgMA) oligomers, were used for simultaneous funtionalization and reduction of graphite oxide (fGO). In this study, the effect of molecular weight and compatibility of the surfactants on the morphology and properties of the nanocomposites are reported. Wide-angle X-ray diffraction (WAXD) exhibited a definite interlayer thickness for GOA (alkylamine intercalated GO), however, the diffraction peaks were nearly suppressed for fGOs combining ODA with either POP (GOAP) or PPgMA (GOAE). The uniform dispersion of the fGO flakes in the polypropylene matrix resulted in the significant increase in both the degradation temperature and the crystallization temperature. A single characteristic melting peak of monoclinic $(\alpha)$ crystalline phase was observed from DSC traces, which was consistent with WAXD results. Dynamic mechanical analysis clearly indicated increase in both the storage modulus and the glass transition temperature of the nanocomposites due to the enhanced affinity between fGO and the polypropylene matrix. However, GOAP composite showed lower $E^{\prime}$ and $T_{\mathrm{g}}$ than GOAE because POP is less compatible with the matrix than PPgMA oligomer. Dielectric analysis also showed significant increase in both dielectric permittivity and dielectric loss at low frequency regimes with GOAE showing maximum dielectric properties. The finely dispersed GOAE and its compatibility with polymer matrix manifested the interfacial polarization, which gave rise to much greater $\varepsilon^{\prime}$ and $\varepsilon^{\prime \prime}$ than other nanocomposites.
\end{abstract}

Keywords: nanocomposites, maleated polypropylene, graphite oxide, functionalization

\section{Introduction}

Conductive polymer composites have aroused wide interests from both academia and industry in the field of functional materials. Addition of diverse conducting fillers such as carbon black [1, 2], graphite [3], and metal fiber or powder [4] into thermoplastic polymers through melt mixing is an effective approach to fabricate conductive composites. Because a great amount of the fillers, generally greater than $15 \mathrm{wt} \%$ [5], were required for the host polymer to become conductive, resulting in both poor processability and inferior mechanical properties, the practical applications of these conventional composites were largely restricted. On the other hand, commercial exploitation of isotactic polypropylene has been expanded rapidly due to its attractive characters of low cost, low weight, heat distortion above $100^{\circ} \mathrm{C}$, and extraordinary versatility in terms of properties, applications and recycling. The introduction of nanoscopic fillers of high anisotropy enhances a wide range of performance of the polypropylene nanocomposites, such as mechanical, thermal and conductive properties, at a relatively small loading [6].

Graphite is a layered mineral composed of weakly bonded graphene sheets with a large aspect ratio.

\footnotetext{
${ }^{*}$ Corresponding author, e-mail: yehwang@thu.edu.tw (C) BME-PT
} 
Traditionally, oxidation of the graphite yields expandable graphite oxide (GO), which is able to be ultrasonically exfoliated in an aqueous solution or polar solvents. As demonstrated recently by various research groups [7-10], exfoliated graphite nanoplatelets, which combine the lower price and layered structure of clays with the superior thermal and electrical properties of carbon nanotubes, can be an effective alternative to both nanoclays and nanotubes. The straightforward and easily upscalable liquid-phase exfoliation of GO under mild temperatures offers a practical way to large scale graphene production [11]. While delamination of GO in aqueous media is well characterized [12], the dispersion of GO in organic solvents has not been well explored. Only with organically intercalated GO, is it possible to form monolayer colloidal dispersion in organic solvents, which would help in the preparation of GO composites with polymer species that are insoluble in water. Furthermore, the plentiful oxygencontaining groups on GO provide active sites for chemical modification of GO surface [13-17]. Chemicals with long alkyl chains $[13,16,18-21]$, such as octadecylamine (ODA), have been used to make hydrophilic GO hydrophobic. It is clear that ODA was mainly used as a surface modifier to improve the dispersion of GO in non-polar polymers; however, to improve the electrical conductivity of ODAfunctionalized GO (GOA), chemical reduction agents, such as hydrazine and hydroquinone, were often incorporated.

Note that GO is an electrically insulating material, and the reduction of GO is necessary for restoring the electrical conductivity of the parent graphite $[22,23]$. Indeed we have demonstrated an efficient approach through ultrasonication for fast functionalizion and in situ reduction of GO with ODA without the addition of conventional chemical reducing agents [24]. The polypropylene nanocomposites filled with GOA exhibited a sharp transition from insulating to conducting with a low percolation threshold at ca. 0.2 vol.\% (GOA).

Past research focused primarily on the GO intercalation with various amino acids or series of primary amines [20, 25, 26]. Multiple amines such as alkyl diamine and triamine are also effective intercalating agents [14, 27]. In all cases, there is a systematic increment of the basal spacing, which can only achieve the maximum spacing of around $3 \mathrm{~nm}$ with a chain length of $\mathrm{C}_{18}(\mathrm{ODA})$, compared to $0.8 \mathrm{~nm}$ of the parent GO. Briefly speaking, the low-molecular-weight surfactants are inadequate for dispersing the layered materials into most polymers [28]. On the other hand, high-molecular weight oligomeric intercalants are seldom used for GO functionalization. ODA functionalized GO has been successfully dispersed in polyethylene glycol oligomer of 4000 DA, and the obtained nanocomposites showed markedly improved properties [29]. Unfortunately PEG is water soluble and incompatible with nonpolar polypropylene. Thus a dual-functional surfactant with hydrophobic backbone and telechelic amines would be an ideal molecular architecture needed to intercalate GO with interlayer enlargement. Here we shall reveal the preparation of layered GO with much greater $d$ spacing by incorporating telechelic POP-diamine of Jeffamine ${ }^{\circledR}$ amines, which had been successfully used in enlarging silicate interlayer spacing [30].

Despite great stride made for the incorporation of GO into polar polymer matrices [22, 23, 31], the nonpolar matrices such as polypropylene (PP) and polyethylene (PE) still pose a significant challenge to achieve homogenous and stable dispersion of graphene [32,33]. Though the effective dispersion of graphene throughout the polymer matrix is critical in order to take full advantage of the unique properties of graphene-based nanocomposites, predominant graphene aggregations is common in polyolefins because they tend to interact poorly with graphene-structured materials due to low interaction energy between them.

In addition, the melt blending technique is widely used for the preparation of graphene/PP composites [34-37]. However, a generally poor dispersion of graphene and a risk of degradation of the polymer matrix often result from melt blending. An alternative to prepare nanoscale dispersed graphene/PP composites via in-situ Ziegler-Natta polymerization in the presence of graphene supported catalyst has been reported [38], but its industrial application is limited by the requirement of sophisticated polymerization techniques. The graphene/PP composites with good filler dispersion can also be prepared through a solution mixing manner [39-41]. In most studies, PPgMA was used either as the matrix polymer $[24,42]$ or as the compatibilizer for PP/functionalized graphite oxide (fGO) nanocomposites $[39,41]$. But the effect of the molecular weight of PPgMA was rarely discussed, and it is apparent that 
a timely study is needed. A commercial PPgMA of low molecular weight and high grafting degree is used in this work. It will be shown that the combination of low molecular weight PPgMA with ODA greatly improve the dispersion and the properties of the PPgMA/GO nanocomposites.

In view of the success of the layered nanocomposites of POP-diamine and PPgMA modified clay [30, 43] or graphite [44, 45], we attempted in this study to prepare the conducting polypropylene nanocomposites of ODA intercalated graphite oxide in combination with the two different types of oligomers via solution blending. The goal of this research is to explore the effect of surfactant molecular weight on the thermal, mechanical, and conductive properties, of the nanocomposites. The present study serves two simultaneous purposes of accommodating graphene sheets at the molecular level and furnishing the highly desirable interfacial bonding with the nonpolar matrix. High degree of dispersion means higher area per volume and better bonding means efficient use of filler presence in the matrix to improve composite properties. Direct impact of higher quality dispersion and interfacial bonding on the mechanical and conductive properties are shown to be greatly enhanced by surfactant combinations compared to single ODA surfactant. The results presented here are thermal and mechanical properties from both differential scanning calorimetry (DSC) and dynamical mechanical analysis (DMA). The dielectric properties and the electric conductivity are studied with a dielectric analyzer (DEA).

\section{Experimental}

\subsection{Materials}

Maleated polypropylene (PB3150, Chemtru USA), abbreviated as $\mathrm{PB}, M_{\mathrm{w}}=330000$ as the polymer matrix. Surfaced Enhanced Flake Graphite (FG, 3775, Asbury USA). 90\% octadecylamine (ODA, Acros USA), poly(propylene glycol) bis (2-aminopropyl ether) under the trade name Jeffamine ${ }^{\circledR}$ amines with number average molecular weight of 4000 (POP4000, Huntsman USA), and maleated polypropylene, $M_{\mathrm{w}}=9100$ (E43, Eastman USA) as GO modifiers. Certified 99.8\% p-xylene (Tedia, USA), sulfuric acid synthesis grade (Scharlau Spain), potassium permanganate regent grade (Showa Japan), and hydrogen peroxide regent grade (Showa Japan) were used as received. All aqueous solutions were prepared in deionized water obtained by purification with a Sartorius Arium 611 system.

\subsection{Chemical oxidation of graphite}

The method due to Hummers and Offeman [19] was adopted to prepare graphite oxide (GO) from graphite flakes through chemical oxidation [20] in the presence of concentrated sulfuric acid and potassium permanganate. The solid GO was separated by centrifugation, washed repeatedly with deionized water and acetone until sulphate could not be detected with $\mathrm{BaCl}_{2}$ and dried overnight in an airoven at $65^{\circ} \mathrm{C}$. The dried GO powder is mainly composed of layered, but compactly fastened nanoplatelets of graphite.

\subsection{Intercalation of GO with combined surfactants}

Based on previous investigations [14-16], the neutral amine surfactants, ODA and POP, and the PPgMA oligomer, E43, were used in this study. In each case, a sample of $100 \mathrm{mg}$ of GO was dispersed in $200 \mathrm{~mL}$ of $\mathrm{p}$-xylene in a glass beaker, followed by the addition of $400 \mathrm{mg}$ of ODA. Upon amine addition the GO solid swelled instantly, and the suspension was sonicated for $3 \mathrm{~h}$. Proper amount of POP or E43 was then added based on the amine content and the mixture was again soincated for another $3 \mathrm{~h}$. The ultrasonic processor VCX750 (Sonics \& Materials), frequency $20 \mathrm{kHz}, 750$ watts, equipped with a medium probe made of high grade titanium alloy was used for preparing the organically modified GO. The stable dispersion of amine surfactant intercalated graphite oxide (GOA) was observed over $24 \mathrm{~h}$. The code names are GOA for ODA only intercalated GO; and GOAP and GOAE for ODA+POP and ODA+E43, respectively.

\subsection{Solution-blended $\mathrm{PB} /$ graphite nanocomposites}

Appropriate amount of PB3150 were completely dissolved in p-xylene in a $250 \mathrm{~mL}$ glass beaker upon heating to $105^{\circ} \mathrm{C}$, and subsequently the heated GOS suspension was added dropwise. After sonication for $4 \mathrm{~h}$, a significant portion of p-xylene was removed under vacuum, and the well dispersed blend was cooled to $70^{\circ} \mathrm{C}$. The separation of the resulting derivatives was achieved with a suction filter in order to remove the excess surfactants and p-xylene. Finally, the precipitate was washed well with acetone, and 
then dried in vacuo at $100^{\circ} \mathrm{C}$ for $48 \mathrm{~h}$. The resulting loose powder was hot pressed to produce the testing specimens. The composition of each composite was confirmed by thermal gravimetric analysis at $5 \mathrm{wt} \%$ of graphite filler. The choice of $5 \mathrm{wt} \%$ loading is based on our previous results, in which the calculated ionic conductivity was $10^{-5} \mathrm{~S} / \mathrm{m}\left(30^{\circ} \mathrm{C}\right)$ at $5 \%$ loading of GOA, which was well above the percolation threshold.

\subsection{Characterization}

Wide-angle X-ray diffraction (WAXD) patterns of different samples were recorded on a Shimadzu XRD-6000 (40 kV/40 mA) diffractometer using Cu $\mathrm{K} \alpha$ radiation to characterize the nano-graphite dispersion and the crystalline structure of PB3150. Infrared spectra were recorded on a Shimadzu FTIR spectrometer (Prestige-21) to identify the chemical groups of graphite due to oxidation and intercalation. The samples were measured in the form of $\mathrm{KBr}$ pellets. SEM images of the morphology of GO and functionalized GO powders were observed by field-emission scanning electron microscope (FESEM) JSM-6400 (JEOL, Japan) with accelerating voltage of $12 \mathrm{kV}$ and working distance of $15 \mathrm{~mm}$. The dispersion of graphite particles within the PPgMA matrix was also studied by SEM. The cryofractured sample surfaces were metallized with platinum using an ion coater IB-3 (Giko, Japan). Transmission electron microscopy (TEM) JEM-1200EX (JEOL, Japan) was used for direct observation of the intercalated lamellar structure of graphite oxide in the nanocomposites. Ultrathin samples were obtained by microtoming the sample plates.

The nonisothermal degradation behavior of PB3150 and its composites with fGOs was characterized by using a thermogravimetric analyzer (TGA Q500, TA Instrument). All measurements were performed under a nitrogen atmosphere from room temperature to $800^{\circ} \mathrm{C}$ at a heating rate of $20^{\circ} \mathrm{C} / \mathrm{min}$. Thermal properties of the composites were characterized using a Perkin-Elmer DSC Pyris 1 (Perkin Elmer, Boston, MA). The specimens were first heated to $200^{\circ} \mathrm{C}$ and held for 5 mins to ensure complete melting. The cooling traces were recorded with a cooling rate of $10^{\circ} \mathrm{C} / \mathrm{min}$ from 200 to $0^{\circ} \mathrm{C}$; and the melting traces were recorded by heating again to $200^{\circ} \mathrm{C}$ with a heating rate of $10^{\circ} \mathrm{C} / \mathrm{min}$. Dynamic mechanical analyzer (DMA), Perkin-Elmer 7e, was used to assess the mechanical performance of the composites. For the dielectric measurements of the pristine PB3150 and the nanocomposites covering the temperature range from 30 to $130^{\circ} \mathrm{C}$ and the frequency range from 1 to $10^{4} \mathrm{~Hz}$ were carried out with a TA highperformance dielectric spectrometer DEA 2970. Note that compression molded specimens for both DMA and DEA were prepared on a hot press with a preheated mold at $180^{\circ} \mathrm{C}$ and $100 \mathrm{psi}$ (about $0.7 \mathrm{MPa}$ ) for $10 \mathrm{~min}$.

\section{Results and discussion}

\subsection{Morphological characterization of functionalized graphite oxide}

We first carried out the characterization of the nanofiller. The structure of the filler was investigated under a scanning electron microscope, shown in Figures 1a-1d for the graphite flakes of GO, GOA, GOAP and GOAE, respectively, after the sonicated dispersion dried on a glass for $24 \mathrm{hrs}$. It can be seen from Figure 1 that most graphite flakes were fragmented under extensive oxidation and ultrasonication, and produced graphite sheets with diameters ranging from about 1 to $10 \mu \mathrm{m}$. The starting material is the flake of graphite oxide (GO) in the form of thick plate as shown in Figure 1a with a magnification of $5000 \times$. The arithmetic means of the particle dimensions were obtained by averaging at least 20 particles from the micrographs taken at different regions of the same specimen. Note that the micrographs of functionalized GO flakes are imaged with a magnification of $10000 \times$. The GOA flake (Figure $1 \mathrm{~b}$ ), with the thickness at ca. $80 \mathrm{~nm}$, is apparently thinner than that of GO due to amine intercalation. Furthermore, the intercalating effect of oligomeric surfactants can be clearly seen in Figure $1 \mathrm{c}$ and $1 \mathrm{~d}$, where the stack of graphite sheet was exfoliated into thin plates, whose average thickness was around $50 \mathrm{~nm}$ for GOAP and $30 \mathrm{~nm}$ for GOAE, were generally thinner than that of GOA.

The powder X-ray diffraction (pXRD) patterns of GOS, the as prepared alkylamine intercalated GOA, GOAP, and GOAE are compared with that of unmodified GO in Figure 2. As expected, GO has a prominent, characteristic peak at $2 \theta=11.4^{\circ}$, corresponding to an inter-graphene sheet spacing of $0.81 \mathrm{~nm}$. However, the diffraction peak of GOA shifted to the left of GO due to the effect of alkylamine intercalation. There is an apparent increase of the $d_{001}$ value up to $2.32 \mathrm{~nm}$ for GOA. The increased value confirms the incorporation of the ODA molecules in the 


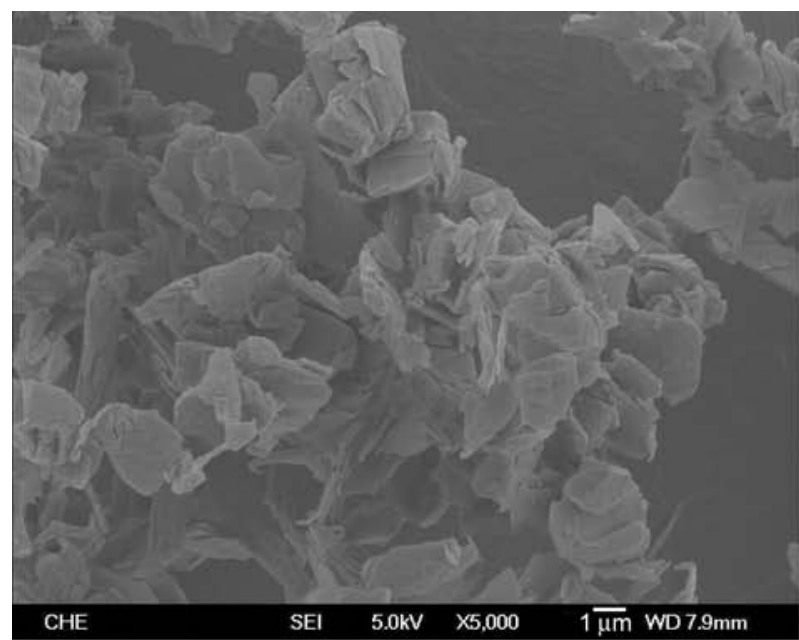

a)

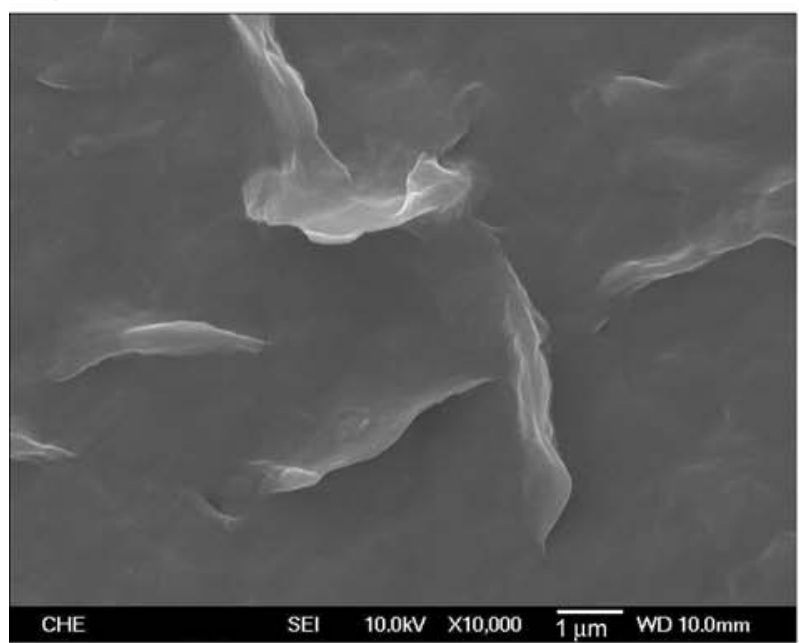

c)

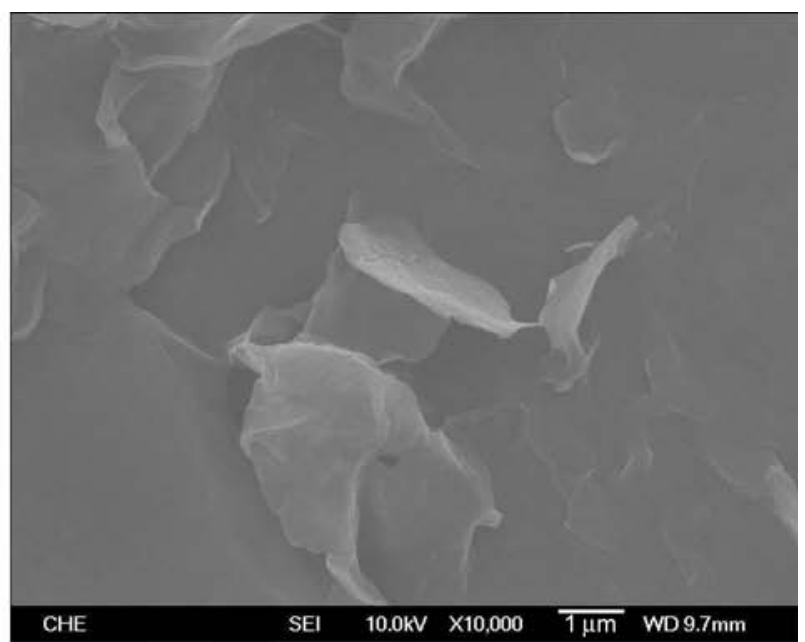

b)

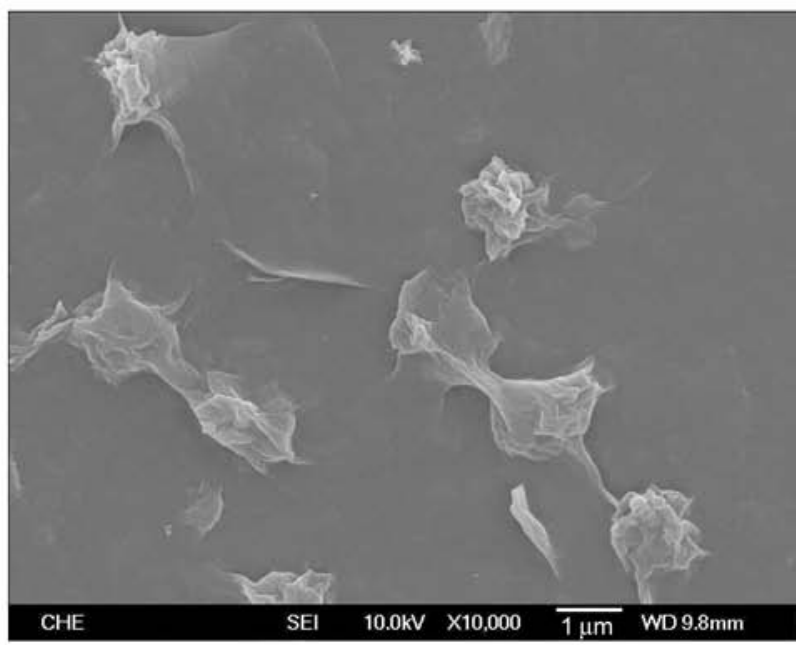

d)

Figure 1. SEM micrographs of functionalized graphite oxide. (a) GO (5000×); (b) GOA; (c) GOAP; and (d) GOAE $(10000 \times)$.

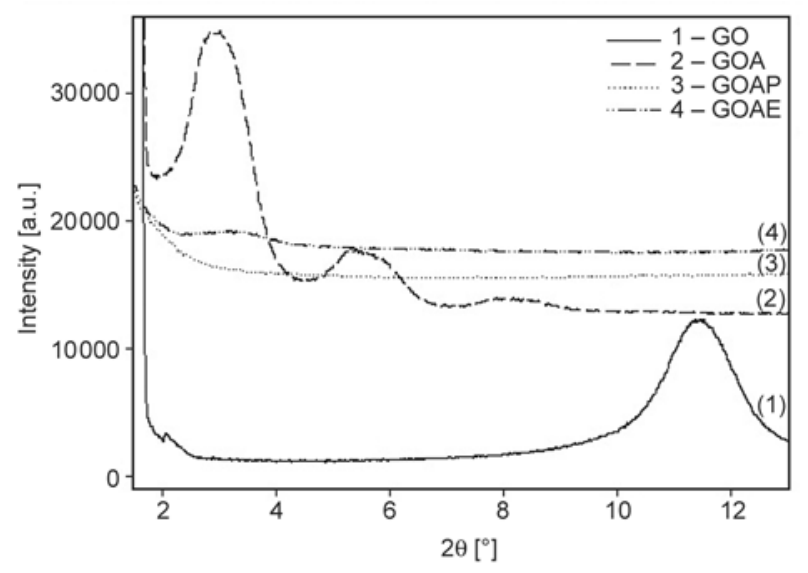

Figure 2. WAXD diffractograms of GO, GOA, GOAP, and GOAE

interlayer space of GO. Further, the intercalation by POP or E43 is even more significant. Compared to the starting GOA, in the POP and E43 intercalated samples the diffraction peak almost disappeared.
The amine or the maleic anhydride groups could be inserted in the interlayer zone of GOA either by hydrogen bonding interactions between the functional molecules and oxygen containing functional groups of GO or by exchange of protons of the acidic groups of GO with alkylamine or anhydride [15]. The intercalation of GO was also confirmed by infrared spectroscopy. FTIR spectra of GO, GOA, GOAP and GOAE are presented in Figure 3. As expected, the spectrum of GO is in good agreement with previous works $[15,16]$. The broad band at $3400 \mathrm{~cm}^{-1}$ is attributed to stretching of the $\mathrm{O}-\mathrm{H}$ bond of $\mathrm{CO}-\mathrm{H}$ or water. The band at $1720 \mathrm{~cm}^{-1}$ is associated with stretching of the $\mathrm{C}=\mathrm{O}$ bond of carbonyl or carboxyl groups. The band present at $1623 \mathrm{~cm}^{-1}$ is attributed to deformations of the $\mathrm{O}-\mathrm{H}$ bending vibration. Stretching vibrations of the $\mathrm{C}-\mathrm{O}$ bond is observed as the intense band present at $1043 \mathrm{~cm}^{-1}$. In addition to the disappearance of the 


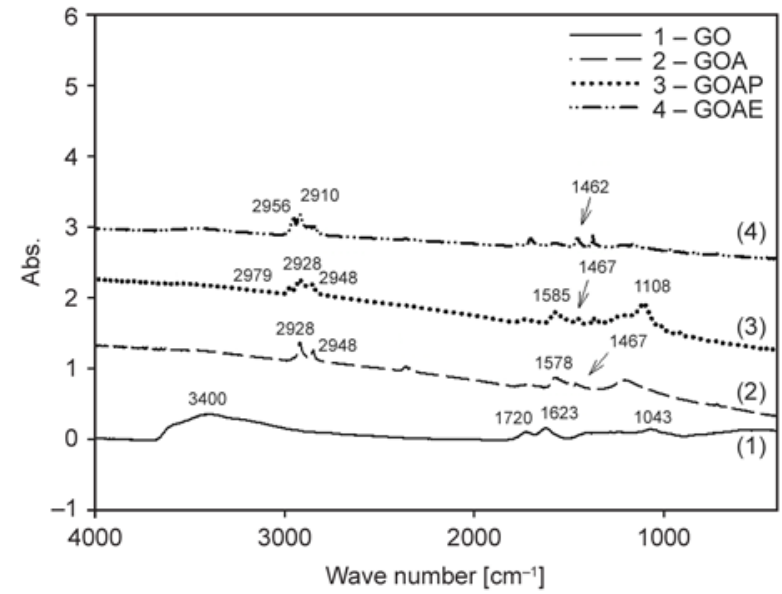

Figure 3. FTIR spectra of GO, GOA, GOAP, and GOAE

absorption bands at 3400 and $1623 \mathrm{~cm}^{-1}$, the FTIR spectra of GOA differ from that of GO in the signals observed at 1043, 1467, 1578, 2848, and $2928 \mathrm{~cm}^{-1}$. The intensity of the first peak is reduced significantly. The next two peaks are assigned to the bending vibration of $-\mathrm{CH}_{2-}$, and vibration of the $\mathrm{N}-\mathrm{H}$ groups of the intercalants, respectively. The strongest signals, observed at higher frequencies, are attributed to asymmetric $\left(2928 \mathrm{~cm}^{-1}\right)$ and symmetric $\left(2848 \mathrm{~cm}^{-1}\right)$ stretching of the methylene group of the alkylamine. For GOAP spectra, it shows one additional band relative to that of GOA. The band at $1108 \mathrm{~cm}^{-1}$ is assigned to the $\mathrm{C}-\mathrm{O}$ vibrations along the POP backbone. Further, the reduction in interlayer water content in GOA and GOAP is also confirmed from the fact that the intensities of the peaks at 3400 and $1623 \mathrm{~cm}^{-1}$ clearly decrease compared to that of GO. Finally, for GOAE spectra, besides the disappearance of both bands at 3400 and $1623 \mathrm{~cm}^{-1}$, the band at $1720 \mathrm{~cm}^{-1}$ is assigned to the carbonyl vibration in carboxylic acid. The absorption bands in the region of 2848 to $2956 \mathrm{~cm}^{-1}$ are related to the characteristic of the methyl group and the methylene unit on the polypropylene backbone. Further, the disappearance of the bands at 3400 and $1623 \mathrm{~cm}^{-1}$ (due to $\mathrm{O}-\mathrm{H}$ stretching and bending, respectively), and at $1043 \mathrm{~cm}^{-1}$ (due to $\mathrm{C}-\mathrm{O}$ stretching) strongly indicated the reduction of GO during functionalization. In addition, though the results are not presented here, we also observed the color change of the GO suspension from light brown before sonication to deep black (color of parent graphite) after suspension.

\subsection{Possible intercalation/exfoliation mechanism}

Now let us consider the intercalation/exfoliation mechanism of the GO with various surfactants. The intercalation of ODA into the graphene layers has been well studied [18-21]. Figure 4 presents a schematic representation of the intercalation/exfoliation process of the three surfactants, i.e., ODA, POP, and E43, with GO. In the first stage the strong interaction of hydrogen bonding between the amino groups of ODA and the oxygen groups of the graphite oxide opened up the interlayer spacing of $\mathrm{GO}$, and the attraction among the graphite layers should be weakened. Next the ODA modified GO (GOA) further intercalated/exfoliated with the oligomers POP diamine (upper route) and E43 (lower route). We acknowledge that the chemistry of POP and E43 with GO is different. Nonetheless its effect is insignificant because both surfactants are able to react with the dominant oxidation groups of GO [15] as seen in Figure 4. Hence the molecular weight (chain length) of the oligomers is responsible for the improved dispersion of fGO in the composites. Since the miscibility of E43 (PPgMA oligomer) with polypropylene is good enough to blend at the molecular level, it will form uniformly dispersed fGO nanocomposite in the polypropylene matrix. On the other hand, since the miscibility between POP diamine and polypropylene is poor, the phase separation occurs within the nanocomposite (see later discussion). Therefore, it is quite reasonable to say not only the intercalation ability of the oligomers but also the miscibility should be a very important factor to achieve the exfoliated homogeneous dispersion of the fGOs in this novel approach using oligomers as a compatibilizer.

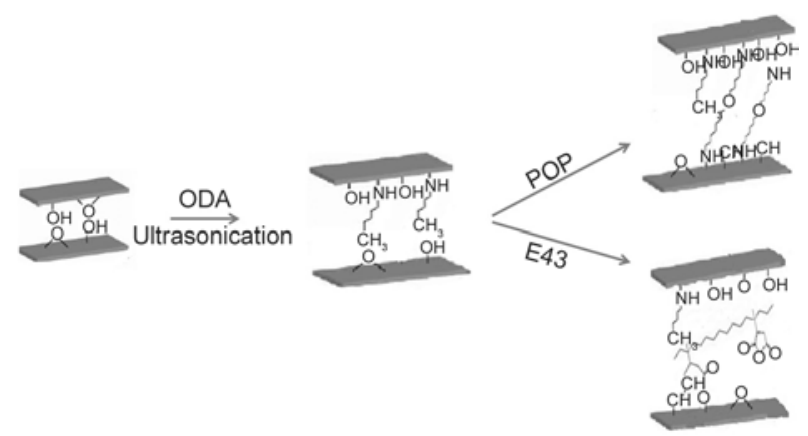

Figure 4. Schematic of the synthetic mechanism of organically modified graphite oxide 


\subsection{Morphology and properties of polymer/graphite nanocomposites}

We first studied the thermal stability and determined the composition of the fGO composites by the thermogravimetric analysis (TGA). Figure 5 shows TGA thermograms (Figure 5a) and their derivative weight curves (Figure $5 \mathrm{~b}$ ). The enlarged graphs in the range from $350-500^{\circ} \mathrm{C}$ were inserted in the lower left or upper-right corners of Figures $5 \mathrm{a}$ and $5 \mathrm{~b}$, respectively, to see clearly the difference among various hybrids. Those are the measurements of neat $\mathrm{PB}$ and $\mathrm{PB} / \mathrm{GOA}, \mathrm{GOAP}$, and GOAE nanocomposites with $5 \mathrm{wt} \%$ graphite contents. Thermal degradation profiles of the nanocomposites displayed that thermal stability of the nanocomposites was improved with the increasing fGO content. For the quantitative comparison of thermal stabilities among the tested specimens, the maximum thermal degradation temperatures, $T_{\mathrm{d}}$, evaluated from the peak value of DTG curves were summarized in Table 1, together with the weight fractions of graphite and the surfactant of each specimen. Note that the weight fractions of amine content and hence the polymer content were determined from the TGA results of the GOA powders, and the graphite contents were confirmed by the residual weights in Figure 5a. As listed in Table 1, the PB content decreased from 88 to $44 \mathrm{wt} \%$ as the surfactant content increased

Table 1. Onset and peak degradation temperatures and char content of $\mathrm{PB} / \mathrm{fGOs}$

\begin{tabular}{|l|c|c|c|c|c|c|}
\hline \multirow{2}{*}{$\begin{array}{c}\text { Sample } \\
\text { code }\end{array}$} & \multicolumn{2}{|c|}{$\mathbf{T}_{\text {onset }}$} & $\mathbf{T}_{\mathbf{d}}$ & \multicolumn{1}{c|}{$\begin{array}{c}\text { Matrix } \\
{[\mathbf{w t} \% \mathbf{]}}\end{array}$} & $\begin{array}{c}\text { Modifiers } \\
{[\mathbf{w t} \% \mathbf{]}}\end{array}$ & $\begin{array}{c}\text { Char } \\
{[\mathbf{w t} \% \mathbf{0}}\end{array}$ \\
\hline $\mathrm{PB}$ & 273.3 & 450.8 & 100 & - & 0.3 \\
\hline $\mathrm{PB} / \mathrm{GOA}$ & 262.8 & 468.3 & 87.6 & 7.4 & 5.1 \\
\hline $\mathrm{PB} / \mathrm{GOAP}$ & 259.4 & 472.4 & 71.2 & 23.8 & 5.1 \\
\hline $\mathrm{PB} / \mathrm{GOAE}$ & 261.5 & 474.3 & 43.8 & 51.2 & 5.1 \\
\hline
\end{tabular}

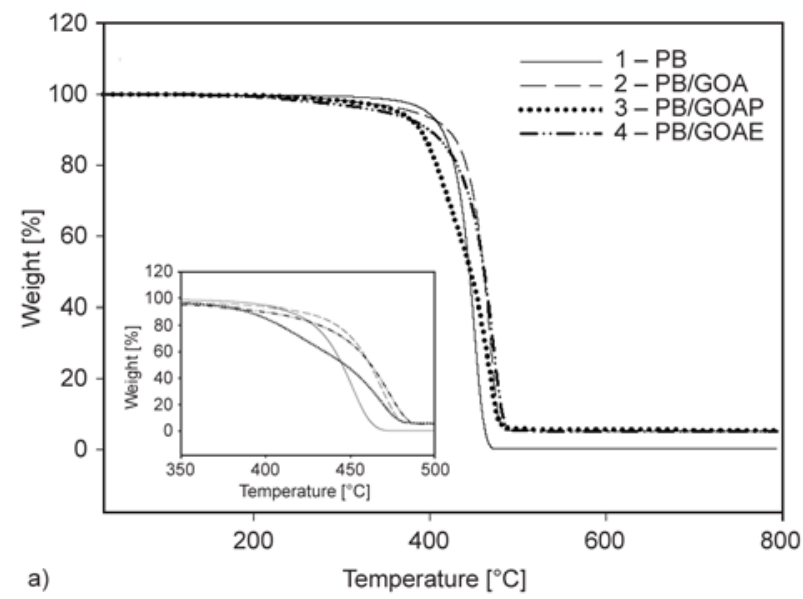

from 7.5 to $50 \mathrm{wt} \%$ with increasing dose of oligomeric surfactants.

Next, the $T_{\mathrm{d}}$ of unfilled PB was determined to be about $450.8^{\circ} \mathrm{C}$. And the $T_{\mathrm{d}}$ 's of the composites increased from ca. $18^{\circ} \mathrm{C}$ of GOA (the lowest) to ca. $24^{\circ} \mathrm{C}$ of GOAE (the highest) against the unfilled matrix. This improved thermal stability of the nanocomposites is believed to originate from the fact that graphite nanoplatelets of GOAs, which were dispersed homogeneously in the PB matrix, serve as the mass transfer barriers against the volatile pyrolized products in the PB matrix, eventually retarding thermal degradation of the nanocomposites. Next, it can be clearly seen that only the DTG curve of the $\mathrm{PB} / \mathrm{GOAP}$ composite showing a small shoulder at ca. $406^{\circ} \mathrm{C}$, which may arise from the incompatibility between POP and PB matrix. The incompatible PB-POP pair will be further elucidated in DMA analysis. Finally, we also noticed that the onset of thermal decomposition was earlier for the nanocomposites compared to pure $\mathrm{PB}$. The free surfactant and other small molecule impurities may cause the nanocomposites decompose earlier than the pure PB. However, after decomposition of the volatile components, the functionalized graphene nanosheets played the major role in enhancing the degradation temperatures of the nanocomposites.

Figures $6 \mathrm{a}, 6 \mathrm{c}$, and $6 \mathrm{e}$ are the images of the cryogenically fractured surfaces of GOA, GOAP and GOAE composites at $5 \mathrm{wt} \%$ loading, respectively, with low magnification of 5000×; and Figures 6b, $6 \mathrm{~d}$, and $6 \mathrm{f}$ at high magnification of $30000 \times$. As can be seen in the low magnification images, with the filler addition, the fractured surfaces become rough with few microcracks near the fGO flakes, consistently with the hypothesis of heterogeneous nucle-

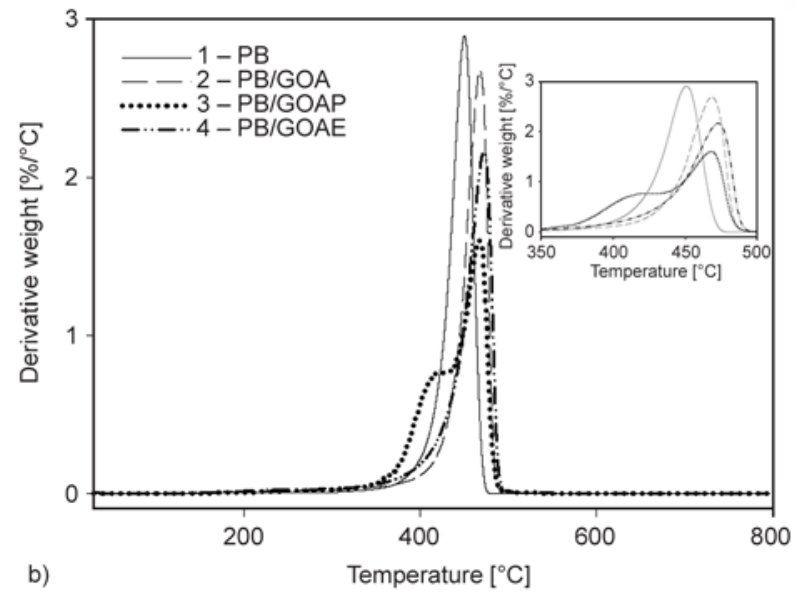

Figure 5. TGA thermograms of neat PB and nanocomposites. (a) weight loass curves; (b) derivative weight loss curves. 

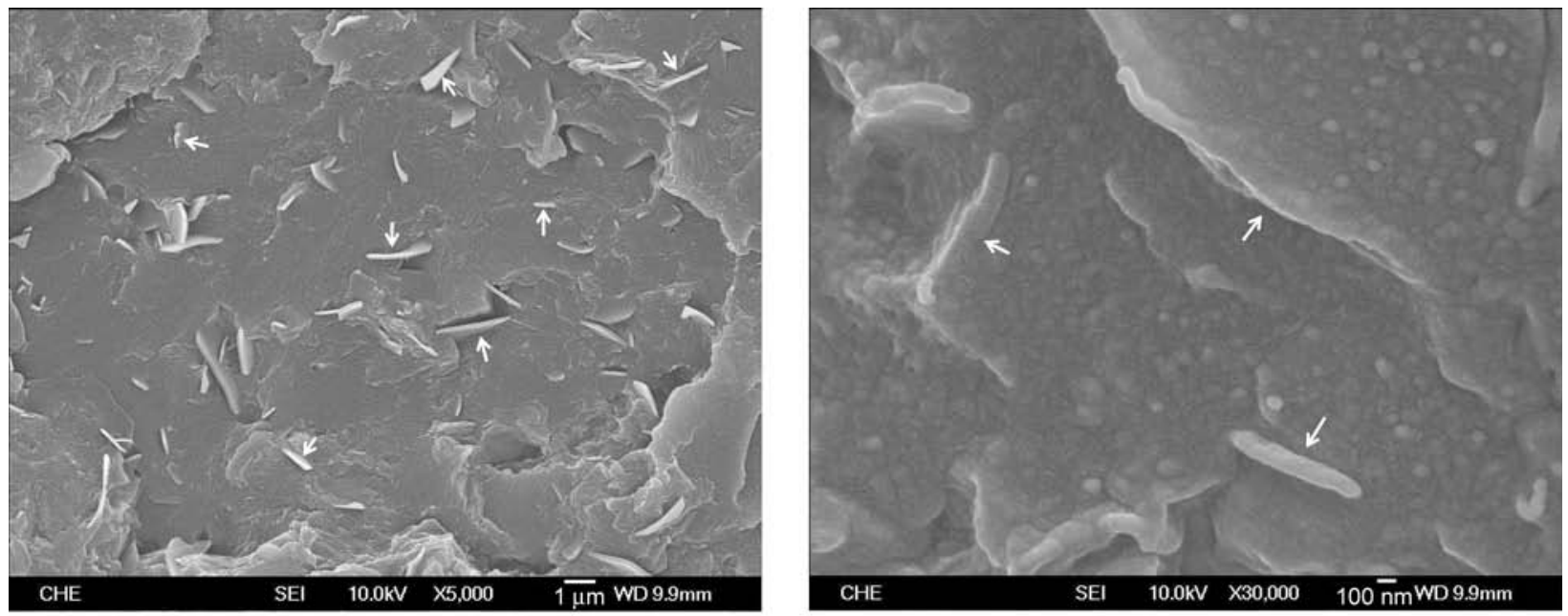

a)
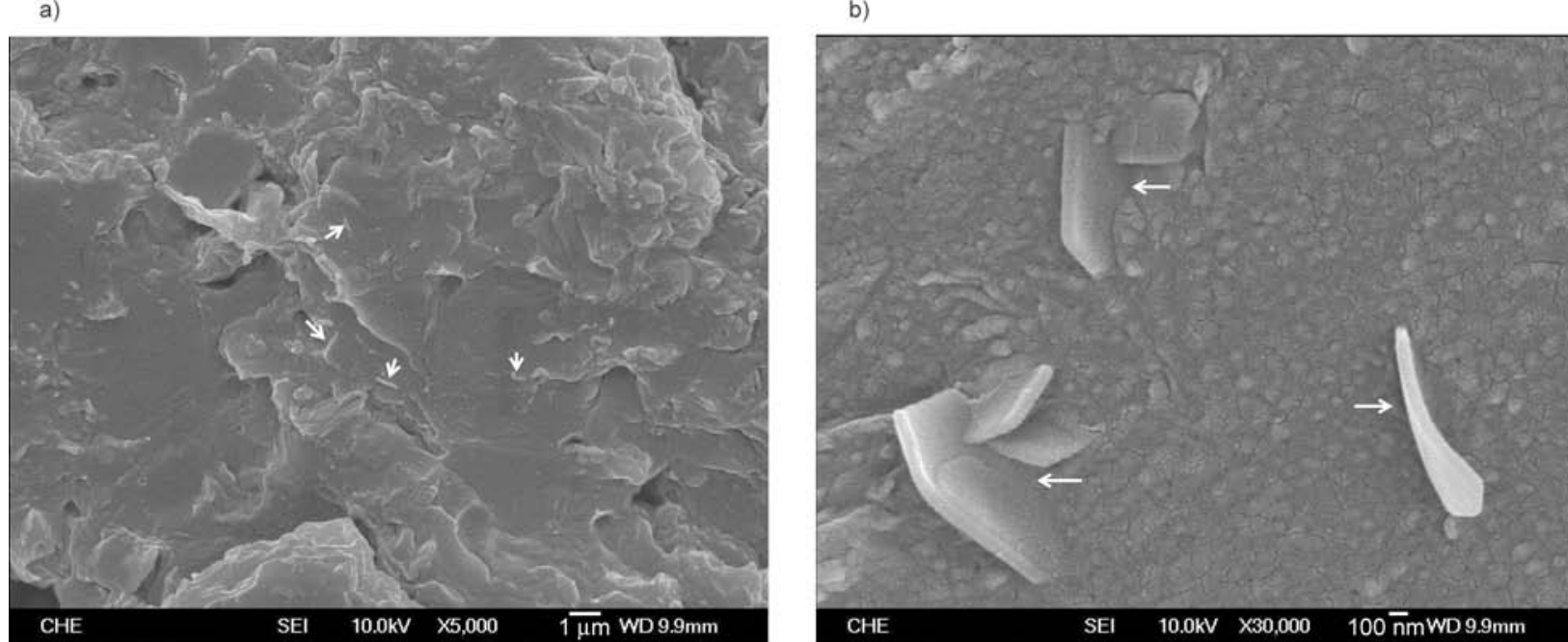

c)
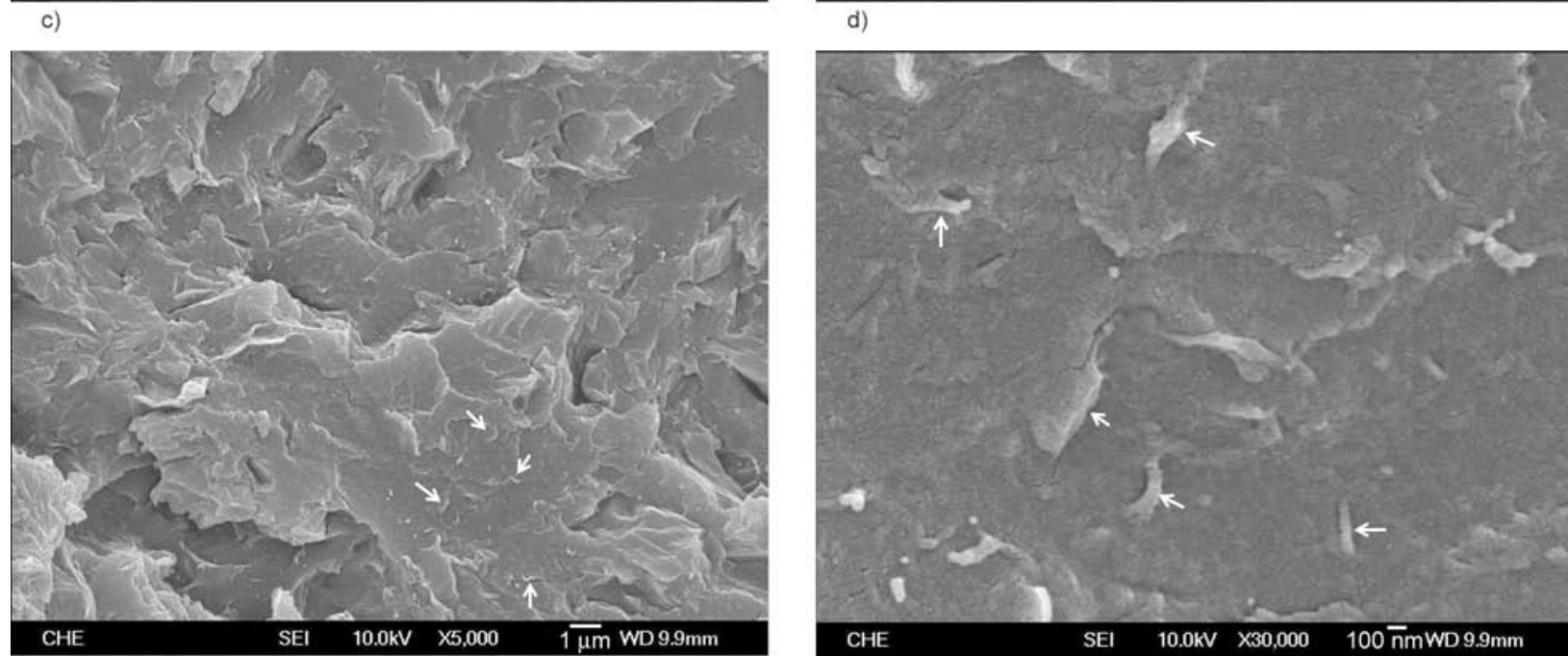

e)

Figure 6. SEM micrographs of the cryogenically fractured surfaces of the nanocomposites at 5 wt $\%$ loading. (a) PB/GOA; (c) PB/GOAP; (e) PB/GOAE at 5000×; (b) PB/GOA; (d) PB/GOAP; (f) PB/GOAE at $30000 \times$.

ation by graphite. It can also be seen that the fractured surfaces of all specimens exhibit uniform dispersion of fGO nanoplatelets particles. The images of the fGO flakes appear much brighter than the surrounding PB matrix, and many platelets are pro- truded from the fractured surface due to weak interfacial adhesion. However, as marked by the arrows in Figures $6 \mathrm{c}$ and $6 \mathrm{e}$, most of the GOAP and GOAE flakes are embedded in the PB matrix. The intercalated or exfoliated graphite nanoplatelets not only 
are uniformly dispersed in the nanocomposites, but exhibit good adhesion between the organic-inorganic constituents. The edge-on view of the nanoplatelets of the organically modified fGOs can be clearly seen from the high magnification images of $30000 \times$ in Figures 6b, 6d and 6f, which show the thickness of the flakes is about the same order as that shown in Figure 1 of the images of the fGO powders. Note that the interfaces remain intact hardly seeing any microcracks or defects due to strong interfacial adhesion between fGO flakes and PB matrix.

We also employed XRD to further characterize graphite dispersion in the composites samples. In nanocomposites containing organoclay, increasing exfoliation is associated with a reduction of the peak intensity in XRD characteristic of the repeated layer spacing. We apply the same principle in graphite-based samples. As seen in Figure 7, the X-ray diffractograms of neat PB3150 and the PBgraphite hybrids made by solution blending. Neat PB3150 has several XRD peaks between $2 \theta=14.0$

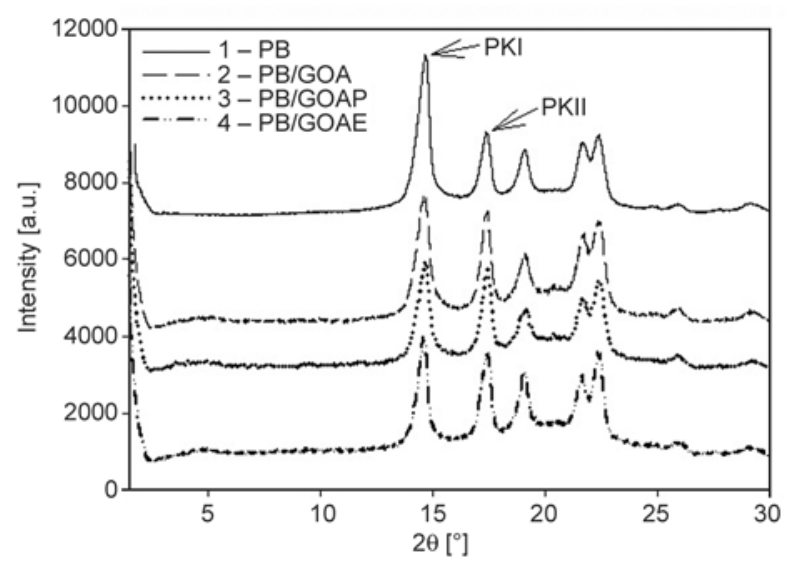

Figure 7. WAXD diffractograms of neat PB3150 and composites at $5 \mathrm{wt} \%$ loading

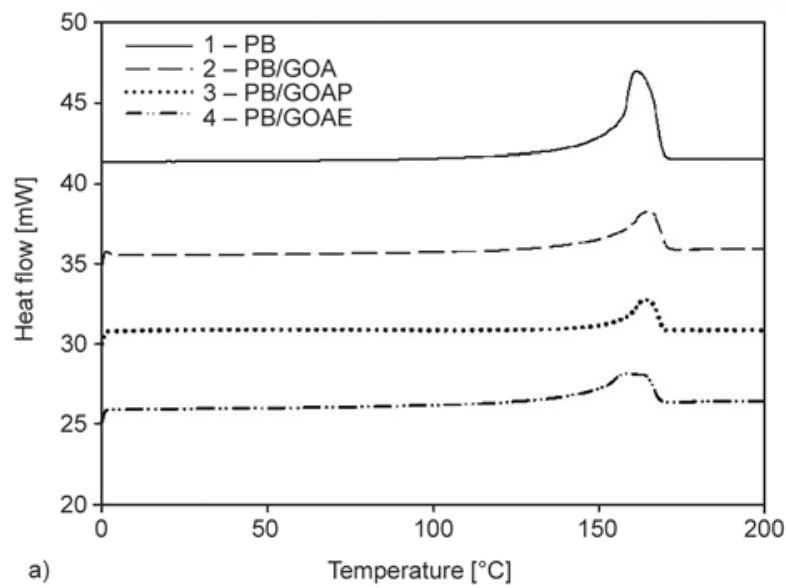

and $28.3^{\circ}$, consistent with the PP crystal unit cell $[19,20]$. All the composite systems exhibit peaks associated with neat PP, although the peak intensities are decreased in the hybrid. The pristine grahite exhibits a diffraction peak at $26.6^{\circ}$, associated with the inter-graphene sheet spacing, which is almost totally suppressed in the $\mathrm{PB} / \mathrm{fGO}$ samples. This strongly suggests that significant exfoliation/dispersion of the GOA and GOAE and GOAP flakes was achieved under ultrasonication. The X-ray diffraction results supplement the morphological observations from electronic microscopy. In addition, the relative intensities of PkI and PkII changed in the diffractogram of $\mathrm{PB} / \mathrm{GOA}$. The intensity ratio of PkII/PkI was considerably more intense for polypropylene/fGO composites than the unfilled matrix. It has been reported [19] that the high relative intensities of PkII to PkI in the presence of graphite was attributed to the strong preferential growth of PP crystallites along the $b$-axis during nucleation, since the PkII corresponds to (040) reflection of $\alpha$-form of crystalline PP. Furthermore, the high intensity of PkII suggests high degree of crystallinity. It can be clearly seen that the intensity of PkII of PPgMA/ graphite nanocomposites is in the descending order GOA $>$ GOAP $>$ GOAE. Note that with the same graphite content at $5 \mathrm{wt} \%$ for each composite, the PB content decreases from $88 \mathrm{wt} \%$ in $\mathrm{PB} / \mathrm{GOA}$ to $44 \mathrm{wt} \%$ in $\mathrm{PB} / \mathrm{GOAE}$ due to the incorporation of oligomeric surfactants. The nucleating effect of fGOs on PB matrix was further investigated in the crystallization and melting behavior of $\mathrm{PB} / \mathrm{fGO}$ with differential scanning calorimetry (DSC).

Figure 8 shows the DSC cooling (Figure 8a) and heating (Figure $8 \mathrm{~b}$ ) curves of PB and the PB composites. In Table 2 we summarized the values of the

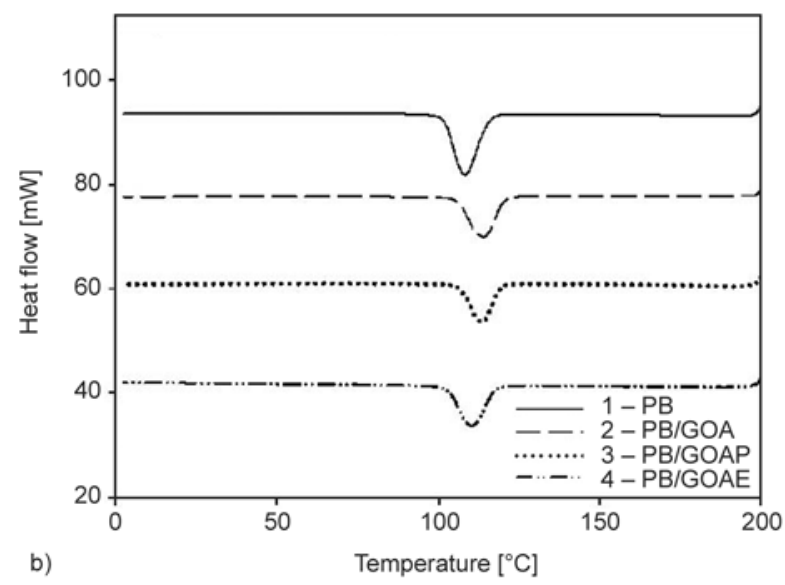

Figure 8. DSC thermograms of PB3150 and nanocomposites (a) cooling curves and (b) heating curves at 5 wt $\%$ loading 
Table 2. Crystallization, melting temperatures and enthalpies of $\mathrm{PB} / \mathrm{fGOs}$

\begin{tabular}{|l|c|c|c|c|}
\hline $\begin{array}{c}\text { Sample } \\
\text { code }\end{array}$ & $\begin{array}{c}\mathbf{T}_{\mathbf{m}} \\
{\left[{ }^{\circ} \mathbf{C}\right]}\end{array}$ & $\begin{array}{c}\Delta \mathbf{H}_{\mathbf{m}} \\
(\text { normalized) } \\
{[\mathbf{J} / \mathbf{g}]}\end{array}$ & $\begin{array}{c}\mathbf{T}_{\mathbf{c}} \\
{\left[{ }^{\circ} \mathbf{C}\right]}\end{array}$ & $\begin{array}{c}\Delta \mathbf{H}_{\mathbf{c}} \\
(\text { normalized) } \\
{[\mathbf{J} / \mathbf{g}]}\end{array}$ \\
\hline $\mathrm{PB}$ & 157.5 & 89.2 & 108.2 & 90.6 \\
\hline $\mathrm{PB} / \mathrm{GOA}$ & 164.7 & 97.8 & 113.9 & 101.3 \\
\hline $\mathrm{PB} / \mathrm{GOAP}$ & 164.2 & 94.3 & 113.2 & 99.2 \\
\hline $\mathrm{PB} / \mathrm{GOAE}$ & 160.3 & $96.6^{*}$ & 110.2 & $95.8^{*}$ \\
\hline
\end{tabular}

"Note: $\Delta H_{\mathrm{m}}$ and $\Delta H_{\mathrm{c}}$ of PB/GOAE hybrid was normalized to the total weight fraction of $\mathrm{PB}$ and $\mathrm{E} 43$ (87.6 wt\%).

temperature and enthalpy of crystallization and melting. The values of $\Delta H_{\mathrm{c}}$ and $\Delta H_{\mathrm{m}}$ were normalized by the weight content of PB in the composite. We first take a look at the $T_{\mathrm{c}}$ values of all the PB composites, which increased about $10^{\circ} \mathrm{C}$ compared with that of neat PB. This was due to the nucleating effect of graphite on the PB crystallization. And the PB/ GOA composite showed the greatest increase in $T_{\mathrm{c}}$. Further, it clearly showed that, from the DSC cooling curves of the $\mathrm{PB}$ composites, the crystallization of $\mathrm{PB}$ in $\mathrm{PB} / \mathrm{GOAP}$ was faster than in $\mathrm{PB} / \mathrm{GOAE}$, as the DSC peak temperature for the former was a little higher than those of the latter. It was because the high content of E43 (44 wt \% in the composite PB/ GOAE), which is fully compatible with PB matrix as seen from DMA measurements, may interfere with the PB crytallization. Accordingly, the normalized degree of crystallinity $\left(\Delta H_{\mathrm{c}}\right.$ and $\left.\Delta H_{\mathrm{m}}\right)$ of $\mathrm{PB}$ in the composites is in the descending order as follows: $\mathrm{PB} / \mathrm{GOA}>\mathrm{GOAP}>\mathrm{GOAE}$. The high enthalpies and the high $T_{\mathrm{c}}$ observed in the $\mathrm{PB} /$ organically functionalized $\mathrm{GO}$ composites point to the apparent effect of nucleation, which could be probably attributed to the enhanced interfacial interaction between $\mathrm{PB}$ and $\mathrm{fGO}$ resulting from the great increase in the

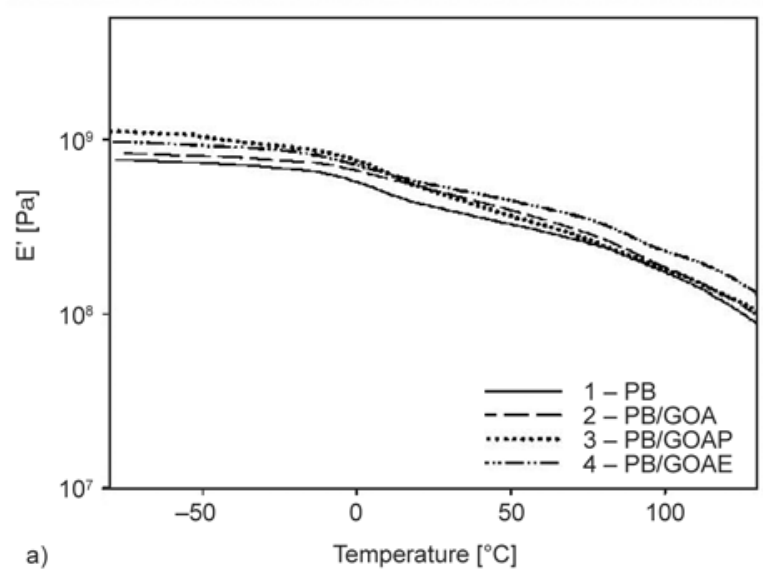

specific surface area of fGO after dispersion/exfoliation in the sonication bath.

The dynamic mechanical behavior of unfilled PB and $\mathrm{PB} /$ graphite nanocomposites are presented in Figures $9 \mathrm{a}$ and $9 \mathrm{~b}$ with $5 \mathrm{wt} \%$ of graphite. The storage (or elastic) moduli $\left(E^{\prime}\right)$ are presented in Figure 9a. The $E^{\prime}$ values of all the samples at nominated temperatures are listed in Table 3 . From the $E^{\prime}$ curves it is apparent that, in the presence of graphite fillers, the $E^{\prime}$ of the composites was greater than that of unfilled $\mathrm{PB}$ throughout the temperature range. The maximum of the glassy $E^{\prime}$ of filled $\mathrm{PB}$ at $-50^{\circ} \mathrm{C}$ and $-10^{\circ} \mathrm{C}$ was observed for PB filled with GOAP. It increased from $723 \mathrm{MPa}$ (unfilled PB) to $1041 \mathrm{MPa}$ $(\mathrm{PB} / \mathrm{GOAP})$ at $-50^{\circ} \mathrm{C}$, which is higher than that of $\mathrm{PB}$ filled with GOAE (924 MPa). Note that the PB content is ca. $57 \mathrm{wt} \%$ in the $\mathrm{PB} / \mathrm{GOAP}$ composite, and the high content of E43 oligomer at ca. $40 \mathrm{wt} \%$ is responsible for the low $E^{\prime}$ of the $\mathrm{PB} / \mathrm{GOAE}$ composite. However, above room temperature (around $30^{\circ} \mathrm{C}$ ), the $E^{\prime}$ of the $\mathrm{PB} / \mathrm{GOAE}$ hybrid became the highest among the tested samples. The incompatibility between POP and the PB matrix may lead to the drop in $E^{\prime}$ at high temperature regime.

Whilst the $E^{\prime}$ of filled PB increased with subsequent additions $\mathrm{fGO}$, it was found that the reinforcing

Table 3. Dynamic storage moduli and glass transition temperature of unfilled $\mathrm{PB}$ and $\mathrm{PB} / \mathrm{fGOs}$ at nominal temperatures

\begin{tabular}{|c|c|c|c|c|}
\hline \multirow{2}{*}{$\begin{array}{c}\text { Sample } \\
\text { code }\end{array}$} & \multicolumn{3}{|c|}{$\mathbf{E}^{\prime}[\mathbf{M P a}]$} & \multirow{2}{*}{$\begin{array}{c}\mathbf{T}_{\mathbf{g}} \\
{\left[{ }^{\circ} \mathbf{C}\right]}\end{array}$} \\
\hline & $-50^{\circ} \mathrm{C}$ & $-10^{\circ} \mathrm{C}$ & $30^{\circ} \mathrm{C}$ & \\
\hline PB & 732.9 & 638.8 & 390.1 & 1.2 \\
\hline $\mathrm{PB} / \mathrm{GOA}$ & 806.0 & 720.6 & 504.6 & 1.0 \\
\hline PB/GOAP & 1041.7 & 844.9 & 470.1 & 1.3 \\
\hline $\mathrm{PB} / \mathrm{GOAE}$ & 923.9 & 792.5 & 525.5 & 2.3 \\
\hline
\end{tabular}

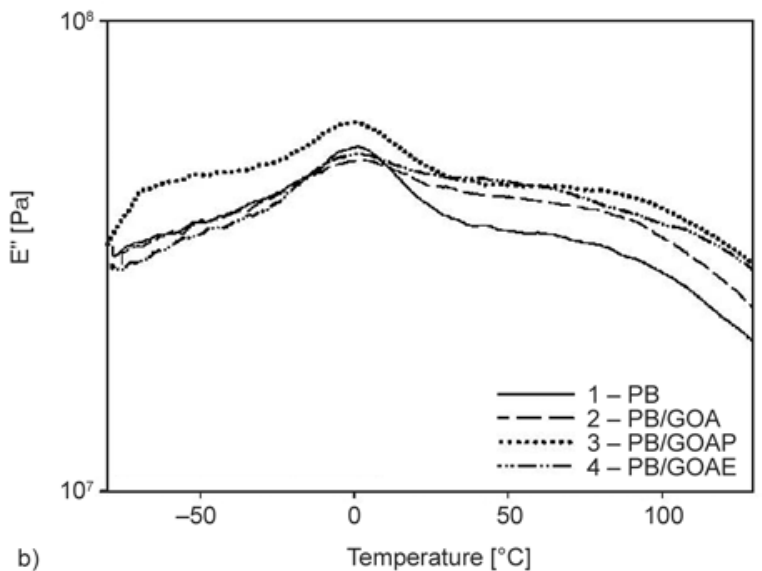

b)

Figure 9. (a) Storage modulus and (b) loss modulus curves of neat $\mathrm{PB}$ and nanocomposites at $5 \mathrm{wt} \%$ loading as a function of temperature 
effect is more prominent in mixed surfactants modified GO than in ODA alone. The lower $E^{\prime}$ of $\mathrm{PB} /$ GOA is believed to be attributed to the greater concentration of graphite stacks (as a result of mild intercalation) than that of $\mathrm{PB} / \mathrm{GOAP}$ and GOAE. This overabundance of GOA stacks resulted in some filler particles likely unable to bond to POP or MA substituents, which in turn limited the improvement in the composite mechanical properties. The glass transition $\left(T_{\mathrm{g}}\right)$, which is the viscoelastic transition of a material, is often drawn from the maxima of $E^{\prime \prime}$ curve as shown in Figure 9b. In this case the $E^{\prime \prime}$ curves were used to obtain the $T_{\mathrm{g}}$. The $T_{\mathrm{g}}$ of the unfilled PB is approximately $1.2^{\circ} \mathrm{C}$. It can be clearly seen that the $T_{\mathrm{g}}$ 's of the nanocomposites are generally higher than that of unfilled PB except the GOA hybrid. Similar to the trend of $E^{\prime}$ above $T_{\mathrm{g}}$, the $T_{\mathrm{g}}$ of $\mathrm{PB} / \mathrm{GOAE}$ is the highest at $2.3^{\circ} \mathrm{C}$, followed by both $\mathrm{PB} / \mathrm{GOAP}$ at $1.3^{\circ} \mathrm{C}$ and $\mathrm{PB} / \mathrm{GOA}$ at $1.0^{\circ} \mathrm{C}$. The increase in $T_{\mathrm{g}}$ is ascribed to a decrease in mobility of the polymer chains, due to the strong interactions, hydrogen bonding between the polar groups of $\mathrm{PB}$ and fGO. This observation is also consistent with the behavior of other filled polymeric systems [21]. Finally, the $T_{\mathrm{g}}$ of POP oligomer is also clearly seen form $E^{\prime \prime}$ curve of $\mathrm{PB} / \mathrm{GOAP}$ at $-67.7^{\circ} \mathrm{C}$, while the $\mathrm{PB} / \mathrm{E} 43$ system only showed single $T_{\mathrm{g}}$ representing a fully compatible blend.

The dielectric measurements of the PB/fGO nanocomposites, extending over a frequency range from $10^{0}$ to $10^{5} \mathrm{~Hz}$ at $110^{\circ} \mathrm{C}$, are shown in Figure 10a and 10b. As can be seen form Figure 10a, the dielectric constant, $\varepsilon^{\prime}$, of $\mathrm{PB} / \mathrm{fGO}$ hybrids (at ca. $10^{3}$ ) is much higher than the unfilled matrix (not shown here) due to the interfacial polarization around the exfoliated GO nanoplatlets [46]. Note that the neat matrix

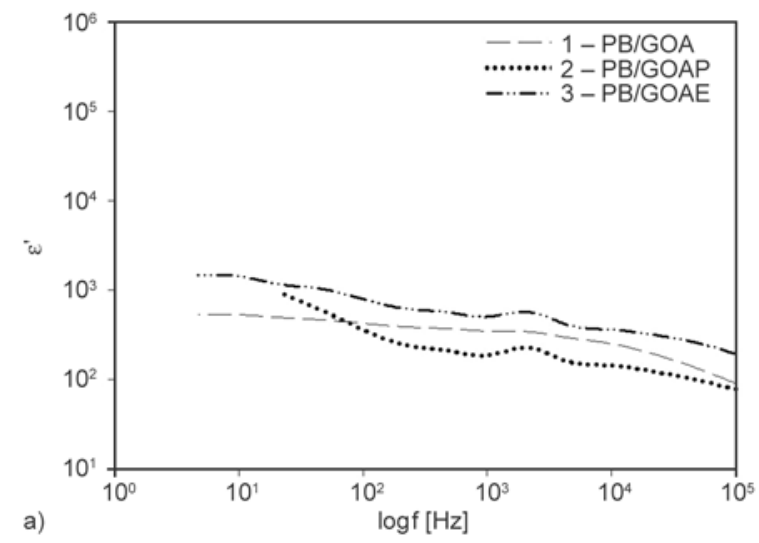

maintains a constant $\varepsilon^{\prime}$ at 2.2 without dielectrically active relaxation process. Moreover, as expected, the $\varepsilon^{\prime}$ decreased with increasing frequency, and the $\mathrm{PB} / \mathrm{GOAE}$ composite displays the greatest $\varepsilon^{\prime}$ among the composites because of the high degree of exfoliation of the $\mathrm{fGO}$ in the hybrid.

The dielectric loss, $\varepsilon^{\prime \prime}$, of the $\mathrm{PB} / \mathrm{fGO}$ composites at $110^{\circ} \mathrm{C}$ were presented in Figure 10b. As expected, the $\varepsilon^{\prime \prime}$ of $\mathrm{PB} / \mathrm{GOAE}$ is about twice that of $\mathrm{PB} / \mathrm{GOAP}$, and about four times that of $\mathrm{PB} / \mathrm{GOA}$ through the experimental temperature range. The functionalization of GO through the intercalation of various surfactants increased the interlayer spacing of the intercalated graphite layered stacks, and facilitated the exfoliation of the graphite nanolayers in the composites. Note that the molecular interaction between the polymer chain segments and nanolayers is greatly enhanced in the PB/GOAE hybrids due to enormous increase in the interfacial area [47] arising from extensive exfoliation by E43 oligomer which is fully compatible with the PB matrix. Hence, in this configuration, the heterogeneous graphite nanolayer inclusions often cause dielectric polarization as a result of the accumulation of charge carriers at the interface of two media with different permittivities or conductivities. Therefore, it can form an effective nanosized capacitor structure [47, 48], and provide increased values of bulk permittivity and loss factor in such a nanostructured morphology.

Figure 11 show the changes of the ac conductivities at $110^{\circ} \mathrm{C}$ of $\mathrm{PB} / \mathrm{fGO}$ composites as a function of frequency with the graphite content at 5 wt.\%. Note that the ac conductivity $\sigma_{\mathrm{ac}}$ was calculated from $\varepsilon^{\prime \prime}$ with the Equation (1) [46]:

$\sigma_{\mathrm{ac}}=\omega \cdot \varepsilon_{0} \cdot \varepsilon^{\prime \prime}$

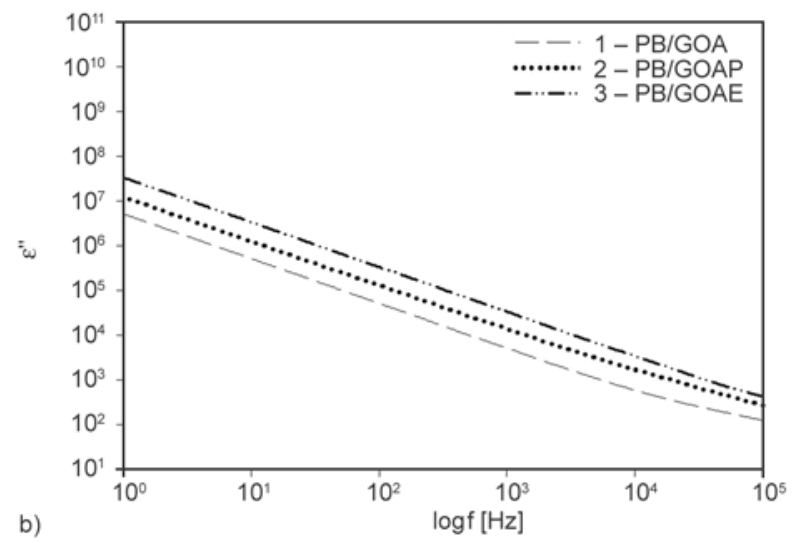

Figure 10. Frequency sweep curves of (a) dielectric permittivity and (b) dielectric loss at $110^{\circ} \mathrm{C}$ for $\mathrm{PB}$ nanocomposites of $5 \mathrm{wt} \%$ 


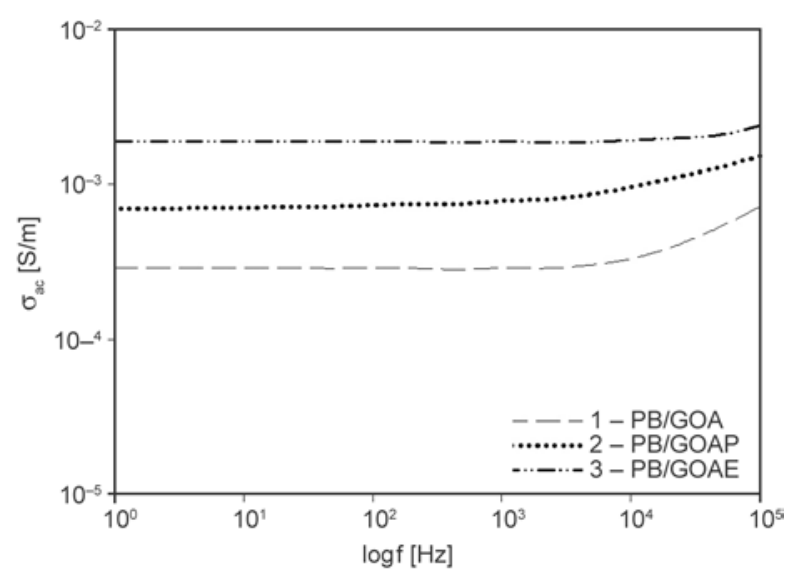

Figure 11. Ionic conductivities vs frequency at $110^{\circ} \mathrm{C}$ for $\mathrm{PB}$ nanocomposites of $5 \mathrm{wt} \%$

where $\omega$ is the angular frequency, $\varepsilon_{0}$ is the absolute permittivity of free space, and $\varepsilon^{\prime \prime}$ is the dielectric loss. It is clearly seen that oac changes drastically with frequency. At low frequency a plateau where $\sigma_{\mathrm{ac}}$ is frequency independent can be observed clearly in the plots. At higher frequencies, $\sigma_{\mathrm{ac}}$ increases rapidly with increasing frequency. The transition region from $d c$ (frequency-independent ionic conductivity) to $a c$ (frequency-dependent) conductivity shifts to higher frequencies with GOAP and GOAE filled composites. Note that the ionic conductivity of neat $\mathrm{PB}$ is evaluated to be in the order of $10^{-13} \mathrm{~S} \cdot \mathrm{m}^{-1}$, which is not shown here. We believe that the significant increase in ionic conductivity for both hybrids is associated with the homogeneous dispersion of GOAP and GOAE in the polymer matrix. Furthermore, the ionic conductivity of the $\mathrm{PB} / \mathrm{GOAE}$ composite was close to $10^{-3} \mathrm{~S} \cdot \mathrm{m}^{-1}$ with only $5 \mathrm{wt} \%$ graphite content. It is apparent that the greater degree of exfoliation/dispersion of GOAE in the PB matrix also gave rise to the higher ionic conductivity than the other modified fGOs. It is noticeable that the ionic conductivity of $\mathrm{PB} / \mathrm{GOAE}$ composite is enough to attain the electrostatic dissipation and/or partial electromagnetic dissipation for thermoplastics, fibers, and films.

\section{Conclusions}

Three different surfactants with two high-molecular weight oligomers were investigated for modifying GO. The ultrasonication was demonstrated to be an efficient approach to simultaneously functionalize and reduce GO without the use of any chemical agents. The functionalization of GO with organic oligomeric surfactans make the hydrophilic GO hydrophobic and thus improves the dispersion of fGO in PB matrix. The morphological and the spectroscopic characterizations indicated that fGO was well intercalated/exfoliated in the polymer matrix. In particular, GOAE showed greater degree of dispersion than GOAP in the composites due to the compatibility between E43 and the polymer matrix. In summary, reduction of exfoliated graphite oxide sheets in organic solvent via ultrasonication results in a material with graphitic characteristics that are comparable to those of pristine graphite. On the nanoscale, this carbon-based material consists of thin graphene-based sheets and possesses a high specific surface area, enhancing the interfacial interaction in the fGO nanocomposites. The further improvement in both the thermal and dielectric properties will be pursued in the future by optimizing the compatibility and adhesion at the fGO-PB interface, and by improving the dispersion and orientation of the graphite nanoplatelets through proper choice of long chain surfactant.

\section{Acknowledgements}

The financial support of this research by the NSC of Taiwan under the grant NSC-99-2221-E-029-001 is gratefully acknowledged.

\section{References}

[1] Tan H., Liu Z. Y., Piao J. H., Chen X. F., Lou X. F., Li S. H.: Electrical behavior of carbon black-filled polymer composites: Effect of interaction between filler and matrix. Journal of Applied Polymer Science, 51, 11591164 (1994).

DOI: 10.1002/app.1994.070510701

[2] Tchoudakov R., Breuer O., Narkis M., Siegmann A.: Conductive polymer blends with low carbon black loading: Polypropylene/polyamide. Polymer Engineering and Science, 36, 1336-1346 (1996).

DOI: $10.1002 /$ pen. 10528

[3] Nagata K., Iwabuki H., Nigo H.: Effect of particle size of graphites on electrical conductivity of graphite/polymer composite. Composite Interfaces, 6, 483-495 (1998).

DOI: $10.1163 / 156855499 X 00161$

[4] Sun J-S., Gokturk H. S., Kalyon D. M.: Volume and surface resistivity of low-density polyethylene filled with stainless steel fibres. Journal of Materials Science, 28, 364-366 (1993).

DOI: $10.1007 / \mathrm{BF} 00357809$

[5] Zweifel Y., Plummer C. J. G., Kausch H-H.: A microscopic investigation of conducting filled polymers. Journal of Materials Science, 33, 1715-1721 (1998). DOI: 10.1023/A:1004316229497 
[6] Gibson A. G.: Processing and properties of reinforced polypropylene. in 'Polypropylene Structure, blends and composites' (ed.: J. Karger-Kocsis) Chapman and Hall, London, Vol. 3, 71-112 (1995).

[7] Wakabayashi K., Pierre C., Dikin D. A., Ruoff R. S., Ramanathan T., Brinson L. C., Torkelson J. M.: Polymer-graphite nanocomposites: Effective dispersion and major property enhancement via solid-state shear pulverization. Macromolecules, 41, 1905-1908 (2008). DOI: $10.1021 / \mathrm{ma} 071687 \mathrm{~b}$

[8] Kim H., Macosko C. W.: Morphology and properties of polyester/exfoliated graphite nanocomposites. Macromolecules, 41, 3317-3327 (2008).

DOI: $10.1021 / \mathrm{ma} 702385 \mathrm{~h}$

[9] Kalaitzidou K., Fukushima H., Drzal L. T.: A new compounding method for exfoliated graphite-polypropylene nanocomposites with enhanced flexural properties and lower percolation threshold. Composites Science and Technology, 67, 2045-2051 (2007).

DOI: 10.1016/j.compscitech.2006.11.014

[10] Wong S-C., Sutherland E. M., Uhl F. M.: Materials processes of graphite nanostructured composites using ball milling. Materials and Manufacturing Processes, 21, 159-166 (2006). DOI: 10.1081/AMP-200068659

[11] Park S., Ruoff R. S.: Chemical methods for the production of graphenes. Nature Nanotechnology, 4, 217 224 (2009). DOI: $10.1038 /$ nnano.2009.58

[12] Li D., Müller M. B., Gilje S., Kaner R. B., Wallace G. G.: Processable aqueous dispersions of graphene nanosheets. Nature Nanotechnol, 3, 101-105 (2008). DOI: $10.1038 /$ nnano.2007.451

[13] Kuila T., Bose S., Hong C. E., Uddin M. E., Khanra P., Kim N. H., Lee J. H.: Preparation of functionalized graphene/linear low density polyethylene composites by a solution mixing method. Carbon, 49, 1033-1037 (2011). DOI: $10.1016 /$ j.carbon.2010.10.031

[14] Tang X-Z., Li W., Yu Z-Z., Rafiee M. A., Rafiee J., Yavari F., Koratkar N.: Enhanced thermal stability in graphene oxide covalently functionalized with 2-amino4,6-didodecylamino-1,3,5-triazine. Carbon, 49, 12581265 (2011). DOI: 10.1016/j.carbon.2010.11.044

[15] Stankovich S., Piner R. D., Nguyen S. T., Ruoff R. S.: Synthesis and exfoliation of isocyanate-treated graphene oxide nanoplatelets. Carbon, 44, 3342-3347 (2006).

DOI: $10.1016 / \mathrm{j}$.carbon.2006.06.004

[16] Cao Y. W., Feng J. C., Wu P. Y.: Alkyl-functionalized graphene nanosheets with improved lipophilicity. Carbon, 48, 1683-1685 (2010).

DOI: $10.1016 /$ j.carbon.2009.12.061
[17] Bao R-Y., Cao J., Liu Z-Y., Yang W., Xie B-H., Yang M-B.: Towards balanced strength and toughness improvement of isotactic polypropylene nanocomposites by surface functionalized graphene oxide. Journal of Material Chemistry A, 2, 3190-3199 (2014). DOI: $10.1039 / \mathrm{c} 3$ ta14554a

[18] Wang G., Shen X., Wang B., Yao J., Park J.: Synthesis and characterisation of hydrophilic and organophilic graphene nanosheets. Carbon, 47, 1359-1364 (2009). DOI: $10.1016 /$ j.carbon.2009.01.027

[19] Lin Z., Liu Y., Wong C-P.: Facile fabrication of superhydrophobic octadecylamine-functionalized graphite oxide film. Langmuir, 26, 16110-16114 (2010). DOI: $10.1021 / 1 \mathrm{a} 102619 \mathrm{n}$

[20] Bourlinos A. B., Gournis D., Petridis D., Szabó T., Szeri A., Dékány I.: Graphite oxide: Chemical reduction to graphite and surface modification with primary aliphatic amines and amino acids. Langmuir, 19, 6050-6055 (2003).

DOI: $10.1021 / \mathrm{la} 026525 \mathrm{~h}$

[21] Niyogi S., Bekyarova E., Itkis M. E., McWilliams J. L., Hamon M. A., Haddon R. C.: Solution properties of graphite and graphene. Journal of the American Chemical Society, 128, 7720-7721 (2006).

DOI: $10.1021 / \mathrm{ja} 060680 \mathrm{r}$

[22] Kim H., Abdala A. A., Macosko C. W.: Graphene/polymer nanocomposites. Macromolecules, 43, 6515-6530 (2010). DOI: $10.1021 / \mathrm{ma100572e}$

[23] Kuilla T., Bhadra S., Yao D., Kim N. H., Bose S., Lee J. H.: Recent advances in graphene based polymer composites. Progress in Polymer Science, 35, 1350-1375 (2010).

DOI: $10.1016 /$ j.progpolymsci.2010.07.005

[24] Wang Y., Tsai H-B.: Thermal, dynamic-mechanical, and dielectric properties of surfactant intercalated graphite oxide filled maleated polypropylene nanocomposites. Journal of Applied Polymer Science, 123, 3154-3163 (2012).

DOI: 10.1002/app.34976

[25] Matsuo Y., Niwa T., Sugie Y.: Preparation and characterization of cationic surfactant-intercalated graphite oxide. Carbon, 37, 897-901 (1999).

DOI: $10.1016 / \mathrm{S} 0008-6223(98) 00226-7$

[26] Nethravathi C., Rajamathi M.: Delamination, colloidal dispersion and reassembly of alkylamine intercalated graphite oxide in alcohols. Carbon, 44, 2635-2641 (2006).

DOI: $10.1016 /$ j.carbon.2006.04.018

[27] Herrera-Alonso M., Abdala A. A., McAllister M. J., Aksay I. A., Prud'homme R. K.: Intercalation and stitching of graphite oxide with diaminoalkanes. Langmuir, 23, 10644-10649 (2007). DOI: $10.1021 / \mathrm{la} 0633839$ 
[28] Alexandre M., Dubois P.: Polymer-layered silicate nanocomposites: Preparation, properties and uses of a new class of materials. Materials Science and Engineering R: Reports, 28, 1-63 (2000).

DOI: $10.1016 / \mathrm{S} 0927-796 \mathrm{X}(00) 00012-7$

[29] Zhang S-P., Song H-O.: Supramolecular graphene oxide-alkylamine hybrid materials: variation of dispersibility and improvement of thermal stability. New Journal of Chemistry, 36, 1733-1738 (2012).

DOI: $10.1039 / \mathrm{c} 2 n j 40214 \mathrm{a}$

[30] Lin J-J., Cheng I-J., Wang R., Lee R-J.: Tailoring basal spacings of montmorillonite by poly(oxyalkylene) diamine intercalation. Macromolecules, 34, 8832-8834 (2001).

DOI: $10.1021 / \mathrm{ma} 011169 \mathrm{f}$

[31] Potts J. R., Dreyer D. R., Bielawski C. W., Ruoff R. S.: Graphene-based polymer nanocomposites. Polymer, 52, 5-25 (2011).

DOI: 10.1016/j.polymer.2010.11.042

[32] Zheng Q., Xue Q., Yan K., Hao L., Li Q., Gao X.: Investigation of molecular interactions between SWNT and polyethylene/polypropylene/polystyrene/polyaniline molecules. Journal of Physical Chemistry C, 111, 4628-4635 (2007).

DOI: $10.1021 / j p 066077 \mathrm{c}$

[33] Lv C., Xue Q., Xia D., Ma M., Xie J., Chen H.: Effect of chemisorption on the interfacial bonding characteristics of graphene-polymer composites. Journal of Physical Chemistry C, 114, 6588-6594 (2010).

DOI: $10.1021 / \mathrm{jp} 100110 \mathrm{n}$

[34] Kalaitzidou K., Fukushima H., Drzal L. T.: Mechanical properties and morphological characterization of exfoliated graphite-polypropylene nanocomposites. Composites Part A: Applied Science and Manufacturing, 38, 1675-1682 (2007).

DOI: 10.1016/j.compositesa.2007.02.003

[35] Song P., Cao Z., Cai Y., Zhao L., Fang Z., Fu S.: Fabrication of exfoliated graphene-based polypropylene nanocomposites with enhanced mechanical and thermal properties. Polymer, 52, 4001-4010 (2011).

DOI: $10.1016 /$ j.polymer.2011.06.045

[36] Xu J-Z., Chen C., Wang Y., Tang H., Li Z-M., Hsiao B. S.: Graphene nanosheets and shear flow induced crystallization in isotactic polypropylene nanocomposites. Macromolecules, 44, 2808-2818 (2011). DOI: $10.1021 / \mathrm{ma1} 1028104$

[37] An J. E., Jeon G. W., Jeong Y. G.: Preparation and properties of polypropylene nanocomposites reinforced with exfoliated graphene. Fibers and Polymers, 13, 507-514 (2012).

DOI: 10.1007/s12221-012-0507-Z

[38] Huang Y., Qin Y., Zhou Y., Niu H., Yu Z-Z., Dong J-Y.: Polypropylene/graphene oxide nanocomposites prepared by in situ Ziegler-Natta polymerization. Chemistry of Materials, 22, 4096-4102 (2010).

DOI: $10.1021 / \mathrm{cm} 100998 \mathrm{e}$
[39] Hsiao M-C., Liao S-H., Lin Y-F., Wang C-A., Pu NW., Tsai H-M., Ma C-C. M.: Preparation and characterization of polypropylene-graft-thermally reduced graphite oxide with an improved compatibility with polypropylene-based nanocomposite. Nanoscale, $\mathbf{3}$, 1516-1522 (2011).

DOI: $10.1039 / \mathrm{c} 0 \mathrm{nr} 00981 \mathrm{~d}$

[40] Yun Y. S., Bae Y. H., Kim D. H., Lee J. Y., Chin I-J., Jin H-J.: Reinforcing effects of adding alkylated graphene oxide to polypropylene. Carbon, 49, 35533559 (2011).

DOI: 10.1016/j.carbon.2011.04.055

[41] Wang D., Zhang X., Zha J-W., Zhao J., Dang Z-M., Hu G-H.: Dielectric properties of reduced graphene oxide/ polypropylene composites with ultralow percolation threshold. Polymer, 54, 1916-1922 (2013). DOI: $10.1016 /$ j.polymer.2013.02.012

[42] Pagé D. J. Y. S., Gopakumar T. G.: Properties and crystallization of maleated polypropylene/graphite flake nanocomposites. Polymer Journal, 38, 920-929 (2006). DOI: 10.1295/polymj.PJ2006020

[43] Wang Y., Huang S-W.: Solution intercalation and relaxation properties of maleated polypropylene/organoclay nanocomposites. Polymer-Plastics Technology and Engineering, 46, 1039-1047 (2007). DOI: $10.1080 / 03602550701522377$

[44] Shen J-W., Chen X-M., Huang W-Y.: Structure and electrical properties of grafted polypropylene/graphite nanocomposites prepared by solution intercalation. Journal of Applied Polymer Science, 88, 1864-1869 (2003).

DOI: $10.1002 / a p p .11892$

[45] Cerezo F. T., Preston C. M. L., Shanks R. A.: Morphology, thermal stability, and mechanical behavior of [poly(propylene)-grafted maleic anhydride]-layered expanded graphite oxide composites. Macromolecular Materials and Engineering, 292, 155-168 (2007).

DOI: $10.1002 /$ mame.200600303

[46] Böhning M., Goering H., Fritz A., Brzezinka K-W., Turky G., Schonhals A., Schartel B.: Dielectric study of molecular mobility in poly(propylene-graft-maleic anhydride)/clay nanocomposites. Macromolecules, 38, 2764-2774 (2005). DOI: $10.1021 / \mathrm{ma} 048315 \mathrm{c}$

[47] Wang Y., Huang S-W., Guo J-Y.: The state of clay dispersion in maleated polypropylene/organoclay nanocomposites via dielectric spectroscopy measurements. e-Polymers, 8, 881-896 (2008). DOI: 10.1515/epoly.2008.8.1.881

[48] Williams E. P. M., Seferis J. C., Wittman C. L., Parker G. A., Lee J. H., Nam J-D.: Dielectric nanocapacitance effect of thermoset polymeric matrix nanocomposites. Journal of Polymer Science Part B: Polymer Physics, 42, 1-4 (2004). DOI: $10.1002 /$ polb. 10663 